Research Article

\title{
Service Quality Evaluation of Terminal Express Delivery Based on an Integrated SERVQUAL-AHP-TOPSIS Approach
}

\author{
Panpan Ma $(\mathbb{D}, \mathrm{Ni}$ Yao, and Xuedong Yang \\ College of Computer and Communication Engineering, Zhengzhou University of Light Industry, Zhengzhou, China \\ Correspondence should be addressed to Panpan Ma; mapanpan128@163.com
}

Received 6 May 2021; Accepted 28 June 2021; Published 9 July 2021

Academic Editor: Yandong $\mathrm{He}$

Copyright ( $) 2021$ Panpan Ma et al. This is an open access article distributed under the Creative Commons Attribution License, which permits unrestricted use, distribution, and reproduction in any medium, provided the original work is properly cited.

\begin{abstract}
With the rapid development of e-commerce and information technology, the express package volume in the Chinese market keeps an explosively increasing tendency. Terminal delivery plays a significant role on the business and reputation promotion of express brand. To identify the service quality of delivery service, an integrated SERVUQAL-AHP-TOPSIS approach is developed to evaluate the quality of service (QoS) of the city express industry. Firstly, the QoS criteria system is established through SERVQUAL-based dimensions. Secondly, the AHP method is employed to derive the relative weights of criteria. Then, the two stages are embedded into the TOPSIS steps to evaluate the service quality of the express alternative. An application case study is conducted following the detailed steps of the proposed integrated decision-making framework, and results demonstrate the effectiveness and validity of the proposed approach on the QoS of terminal delivery evaluation problem.
\end{abstract}

\section{Introduction}

During the last decade, consumers prefer to buy goods from the online shop, contributing to the development of e-commerce. For instance, it has become a prevailing tendency to purchase commodity from Taobao, Jingdong, and other e-shops. With the rapid development of the e-commerce and online shopping, the express industry is motivated by the increasing promotion of this circumstance, and consumers show higher expectations on the logistics service of online consumption [1].

With the soaring increase of e-commerce transaction volume, the express parcel keeps an increasing tendency. For instance, the number of packages in 2019 had reached 60 billion, providing career opportunity and job vacancies for new graduates and practitioners. Different with other business activities in e-commerce, the logistics operation has been paid much attention due to it being a bottleneck activity. With the development of advanced information technologies and logistics techniques, the operational efficiency of logistics has been improved, as well as innovation management practice on logistics mode $[2,3]$.
Terminal delivery, regarding as the crucial process of the city logistics, plays great significance in the logistics service [4]. Terminal delivery of the express logistics is the process interacting with customers directly, and the service conditions at this phase play a great role on the logistics brand. Regarding the final link of the online shopping, the unsatisfied experience of the logistics service will exacerbate the catastrophic damage of the express brands. In practice, the last mile service and terminal delivery are not satisfied as required in Chinese express industry. There are increasing troubles occurring regarding terminal delivery of logistics service, especially during the online shopping scenarios. For instance, the unsatisfied service attitude, irregular distribution tasks, and low delivery efficiency contribute to the unsatisfied perception of online shopping consumers. The cargo damage, inaccurate delivery, and massive express volume lead to the uneven service quality during the last mile delivery. It is very common that express terminal sites usually employ extra staff to satisfy the soaring package delivery during the rush time intervals, such as at June 18 and double 11 . The busy delivery tasks may lead to the unsatisfactory attitudes towards customers, and the irregular 
business operation causes the low efficiency. Under this circumstance, online shopping consumers need to suffer the delay logistics distribution and the barely satisfied service attitude [5].

To improve logistics efficiency of the express delivery, many academic researches and practical applications are studied and implemented. There are a vast majority of publications that have been published focusing on city distribution mechanism and VRP optimizations in express logistics industry. The joint distribution mode is emphasized and crucial technologies of this novel operation are addressed to improve the transportation efficiency. To promote the joint distribution mode, Li studied the profit allocation mechanism of the joint alliance [6]. The innovative VRP applications and distribution modes contribute to efficiency improvement of express delivery $[3,6]$. The double service including home delivery and customers' pick-up are taken into consideration during the VRP optimization [7,8]. Zhou [9] developed a novel nonlinear programming model to assist logistics managers to find an optimal integrated location-routing solution by an improved GA algorithm, and the numerical case showed that it can improve the efficiency of last mile delivery by the formulated model. Li [10] designed an improved ant colony optimization algorithm to improve the logistics efficiency under multidepot scenario. In addition, various uncertain variables are taken into account to address uncertain factors during VRP issues [11-14]. The formulated programming models and designed algorithms contribute to the cost reduction and logistics efficiency improvement [12].

Many last mile delivery researches and applications focused on objectives of low cost and high service efficiency, while ignoring the service quality indicator of the logistics brands. Different with these obvious subobjectives, it is difficult to measure the quality performance of logistics operations compared with cost and transportation time indices. However, with the increasing service requirements, more online shopping consumers start focusing on the consumption experience, which is greatly affected by terminal distribution. Therefore, the QoS is measured and considered as an important optimization goal for logistics problem [9, 15, 16]. In traditional production logistics scenarios, quality performance of logistics activities is usually described by delivery time, accuracy of transported goods, and traceability.

With the booming development of online shopping, the quality of logistics service plays a significant role on consumers' experiences. It is because the logistics service provider becomes the the person who directly contacts with online consumers, instead of salesman or the merchant. Terminal distribution, regarding as the final process of e-commerce logistics service, is the link of direct communication with online shopping consumers. The investigation of customers' experience on its products will assist logistics enterprises to better understand the service they provided [17]. The QoS of terminal distribution not only affects the customers' experience of online shopping, but also influences the brand reputation and further promotion.

However, the last mile service is the direct process of logistics activities, which will be a double-edged sword for organizations [3]. If customers could feel a better distribution service, it helps to win favor on logistics brand, while if consumers have a bad face-to-face experience, it will lead to negative comments. Those customers even share the unsatisfied experience to potential consumers around them. To the state of the art, there is little QoS evaluation practice for terminal distribution under the online shopping scenario. Therefore, we shift our eyes to quality-of-service study since it faces customers directly during terminal delivery process. Considering the great significance of terminal distribution on logistics experience, an integrated MCDM model is developed from SERVQUAL viewpoint to fill the gap, contributing to achieving QoS evaluation and continuous improvement of logistics brands.

The remainder of this research is structured as follows. In Section 2, we present a literature review on the terminal distribution of the express industry and service quality models. Then, an integrated SERVQUAL-AHP-TOPSIS approach is developed to realize the QoS of terminal distribution evaluation in Section 3. Subsequently, a case study is presented to validate the proposed approach. Finally, we close this research with some conclusions.

\section{Literature Review}

2.1. Terminal Distribution. The online shopping logistics driven by e-commerce business and advanced technologies has been focused by researchers and practitioners [1, 18]. Terminal distribution, as the final process of product delivery from the merchant to consumers, plays a great significant role in logistics experiences. It is also called the last mile delivery, which means the logistics activity delivering goods to online shopping customers. The increasingly prevailing online shopping experience requires a shorter logistics time and better delivery service $[19,20]$.

Compared with previous stages of logistics activities, the terminal distribution faces a more challenging situation due to the large scales of customers, varied positions, discrepant demands, and uncertain quantity. Besides, the multichannel delivery has increased the complexity of terminal distribution. The distribution way based on regional locations cannot meet the distribution tasks with a balanced operational efficiency. Therefore, the joint distribution has been introduced to improve operational efficiency of logistics activity by resources sharing and designed mechanisms [3].

The academic research and practical application on terminal distribution of city logistics mainly occur in urban communities, local organizations, and universities for the numerous online shopping requirements. It has become an indispensable part of daily life. Taking the terminal distribution in university campus as an example, almost every logistics service firm has its service dot and serves for faculties' delivery demands [8]. The research area regarding terminal distribution mainly focuses on depot layout, vehicle routing programming, storage optimization, multimodal transportation, stakeholders coordination, and service quality study $[9,10,14,21,22]$. Joint distribution and innovative cloud distribution are studied by developed regions to improve the operational efficiency of terminal 
distribution. Besides, the advanced information technologies are also employed to guarantee the accuracy and safety of last mile service under online shopping atmosphere [3]. The cloud logistics and lean logistics practices also contribute to efficiency improvement [16].

There are several terminal distribution modes, such as self-operated shop, supermarket mode, stall mode, selfservice express cabinet, and home delivery service. These different terminal distribution modes are embedded into traditional VRP or logistics network design or optimization problems regarding last mile distribution. Laura [13] proposed a heuristic framework combined Monte Carlo simulation with a heuristic algorithm to deal with the multidepot vehicle routing problem considering constrained capacity and stochastic requirements. Zhou [21] studied a joint problem considering multiple delivery depots and VRP optimization by formulating a nonlinear programming model, which is resolved by a proposed hybrid multipopulation genetic algorithm. Li [10] formulated a multidepot green VRP programming model whose targets are revenue maximization, and cost/time/emission minimization. And an improved ant colony optimization technique was developed to improve the efficiency of the heuristic algorithm.

Apart from the cost, time indices of logistics service, the service quality is also regarded as an important optimization objective. However, the QoS evaluation is the prerequisite of the programming model of terminal distribution. There are many multicriteria decision-making methods having been widely used for logistics performance evaluation, for instance, SERVQUAL, LSQ model, AHP, and VIKOR approaches [23-27]. However, the QoS evaluation model regarding terminal distribution process is little in previous publications and practices, and this study tries to shift our eyes to the service quality evaluation on terminal distribution since its great significance on customers' experience.

2.2. Service Quality Model. Service quality as a hot topic has been focused and studied by academic researchers and practical managers. It has been a major factor for the triumph of e-commerce and organizational brand $[17,28]$. To assist industrial managers to probe into the performance of organizational service and production function, quality of service (QoS) evaluation application has been developed in different industrial sectors.

Consumers' feedback, regarding as the evaluation information, has provided enough evidence on QoS identification [29]. In addition, expert-based techniques also offer an effective way to discover the current status of organizational service. Sari [30] studied the significant factors in terms of yachtsmen's satisfaction and extracted the six service quality criteria from the ten QoS dimensions to perform quality measurement and scale of the marina service. Wong [31] proposed a service quality model of urban taxis by employing a level-of-service (LOS) standard, contributing to improving publics' better understanding on taxis service situation. Tuzkaya [32] developed an IVIF-PROMETHEE model to measure healthcare service quality, and the interval valued intuitionistic fuzzy set (IVIFS) is used to describe the ambiguity of healthcare information. Hsu [33] applied KANO quality dimensions to evaluate service quality of community buying by integrating e-commerce information with electronic service quality scales.

Jafar [34] developed a QoS evaluation model for container terminal operations from the SERVQUAL dimensions, and specific ranking of all alternatives contributes to determination of industrial managers. Kim [35] proposed a service quality evaluation model for urban rail transfer facilities considering subjective perceptions of transit people, and the Rasch analysis was employed to estimate the "goodness of fit" between difficulty and individual's ability.

Both investigated consumers' data and unstructured textual comments could help industrial managers to identify functional quality and service satisfaction of objective alternatives. Apart from structured consumers' feedbacks and investigated experts' opinion, the speech analytics is also used for the QoS model to improve service quality of pharmaceutical supply chain service providers [36]. Based on the proposed 17 quality key performance indicators (KPIs), a scored-card approach was employed to perform QoS evaluation. Textual comments generated by consumers provided new broad information datasets about service quality by using data mining techniques. Luis [37] studied the airport service quality by using user generate content (UGC) and sentiment analysis method based on collected tweets in social media. Zhou [29] developed a big data-based analytical method to evaluate the vehicle product and service level in terms of online unstructured comments. Google reviews had been proven to be alternative data source for evaluating quality of service for airline industry, and the sentiment analysis and topical modeling technique were integrated to probe into the assessment of traveler consumers [38].

The negative decision information also can be regarded as the decision information for QoS study. Negative online reviews from social media are extracted to evaluate museums' service failure, and twelve service quality indicators are identified and highlighted [39]. To assist discovering the performance gaps of their products, according to the feedbacks of after-sales service systems, the quality improvement priority index was proposed and developed to identify pilot objective for further improvement [40, 41]. Through the evaluation model and proposed index, industrial managers could perform strategic plans and quality actions to achieve product function improvement and brand reputation promotion.

The SERVQUAL scale is widely used to measure quality of service in different sectors for better understanding service status and consumers' requirements of individual organizations. Alex [42] developed a service assessment model to evaluate the perceived quality of financial service conducted at a unit of a credit union. To better identify service quality attributes of Airbnb and probe into specific influences of QoS attributes on customer satisfactions, the mixed approach was developed to discover significant service quality attributes [43]. The SERVQUAL scales for QoS evaluation of different industries are summarized in Table 1. 
TABLE 1: SERVQUAL scales for different industrial sectors.

\begin{tabular}{|c|c|c|}
\hline Industrial sector & QoS scales and dimensions & Sources \\
\hline Marina services & $\begin{array}{l}\text { Tangibles, reliability, responsiveness, credibility, understanding, competence, courtesy, security, } \\
\text { access, communication }\end{array}$ & [30] \\
\hline Airline industry & $\begin{array}{l}\text { Tangibility, reliability security and safety, responsiveness, assurance, effective communication, } \\
\text { addition features, ticket pricing }\end{array}$ & [44-47] \\
\hline Hospital service & $\begin{array}{l}\text { Interaction, technology, time-dependence, physical quality, tangibility, reliability, } \\
\text { responsiveness, assurance, empathy }\end{array}$ & {$[32,48]$} \\
\hline Urb & Time costed, punctuality, facilities & {$[31,49]$} \\
\hline ial sector & Tangibles, reliability, responsiveness, assurance, & {$[42]$} \\
\hline $\begin{array}{l}\text { Container terminal operation } \\
\text { service }\end{array}$ & eliability, & [34] \\
\hline E-commerce service & Site organization, & [50] \\
\hline ilities & $\begin{array}{c}\text { Information provision, mobility convenience, comfort, convenience of facilities, safety, and } \\
\text { security }\end{array}$ & {$[3$} \\
\hline лес & Host service quality, web responsiveness quali & [43] \\
\hline Online shopping & Kano dimensions: attractive, one-dimensional, $\mathrm{n}$ & [33] \\
\hline Community pharmacy & $\begin{array}{c}\text { Health and medicines advice, nonprescription service, relationship quality, technical quality, } \\
\text { environmental quality, health outcomes }\end{array}$ & [51] \\
\hline Trans & $\begin{array}{c}\text { Security, cleanliness, maintenance, integration with other transit systems, facilities for disabled, } \\
\text { information }\end{array}$ & [52] \\
\hline
\end{tabular}

For QoS of terminal distribution evaluation, traditional logistics indexes could be employed to assess service quality, such as order accuracy, timely service, and intactness of purchased goods $[8,53]$. Apart from the specific logistics attributes and terminal distribution metrics, SERVQUAL scales also can be cited to assist to evaluate the QoS of last mile distribution.

\section{Methodology}

To realize the service quality evaluation of terminal express distribution under online shopping atmosphere, the hybrid SERVQUAL-AHP-TOPSIS approach is integrated to assess the express alternatives. This section presents the integrated approach, as well as the implementation steps. The integrated SERVQUAL-AHP-TOPSIS approach is described in Figure 1.

\subsection{Criteria Development by SERVQUAL Dimensions.} The SERVQUAL measurement scales have been widely used in terms of the QoS evaluation for different sectors. There are five dimensions contained in this service quality model, reflected by specific indicators for different industrial scenarios. The five criteria and specific meaning in the express terminal delivery industry are summarized in Table 2.

The Likert five scale scoring system is applied to collect the source data, illustrated in Table 3 [54]. And the specific value reflects the degree of the agreement on the criteria description.

The perceived score in terms of each SERVQUAL dimension is calculated by the following equation:

$$
S Q_{i}=\left(P I_{i}-E I_{i}\right),
$$

where $S Q$ means the perceived service quality subjecting to each criterion, $P I$ is the average score with respect to criteria $i$ from investigated consumers, and $E I$ means the expect score of each criterion $(i=1,2, \ldots, n)$. There are five criteria reflecting the QoS of express terminal industry; that is, $n=5$.

Due to the discrepancy of each individual customer, the weight of each specific meaning is different. Therefore, the weighting average operation is conducted to obtain the overall score of each alternative subject to specific criteria, found in the following equation:

$$
S Q_{i}=\sum_{j=1}^{J} \beta_{j}\left(P I_{i j}-E_{i j}\right),
$$

where $\beta_{j}$ is the relative criteria of each detail meaning, $j$ represents the investigated consumer, and the average SERVQUAL score of each individual consumer is calculated by the following:

$$
\text { score }=\left(\sum_{i=1}^{n} \frac{S Q_{i}}{n}\right) .
$$

3.2. AHP-Weighting Method. As the QoS evaluation of terminal delivery from the consumer-oriented SERVQUAL dimensions, a subjective weighting method called AHP is employed to derive the weights of established criteria. AHP method, proposed by Prof. Saaty, has been proven to be a powerful technique on decision-making problems by decomposing the complex issue into a multilevel hierarchical structure with various criteria [55]. The criteria weight is obtained by the pairwise comparison and is well documented in the previous literature [56, 57]. The detail implementation steps are presented as follows.

Step 1: problem and the objective definition: in this research, the five criteria based on SERVQUAL dimensions are addressed, and the objective in this stage is to determine the relative weight of each SERVQUAL criteria. 


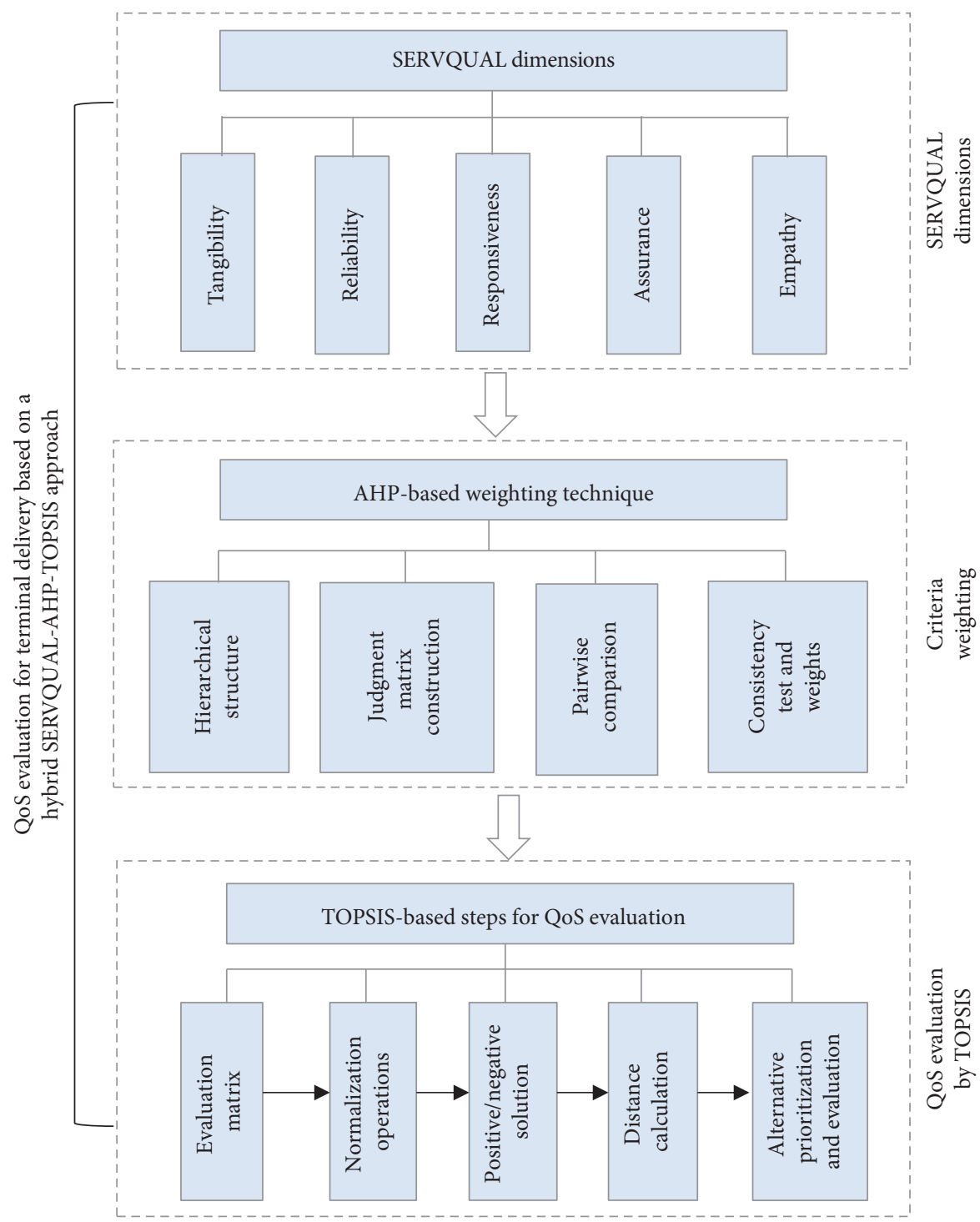

FIGURE 1: Implementation steps of the integrated SERVQUAL-AHP-TOPSIS approach.

TABLe 2: Criteria developed based on SERVQUAL dimensions and specific meanings.

\begin{tabular}{|c|c|c|}
\hline Dimension & Criteria & Specific meanings in express terminal delivery \\
\hline \multirow{4}{*}{ Tangibility (D1) } & $\mathrm{C} 1$ & There are modern terminal delivery facilities \\
\hline & $\mathrm{C} 2$ & The service facility with great attractiveness \\
\hline & $\mathrm{C} 3$ & The faculty has neat wearing \\
\hline & $\mathrm{C} 4$ & The facilitates match the services they provide \\
\hline \multirow{5}{*}{ Reliability (D2) } & C5 & The company can deal with the order as required \\
\hline & C6 & The staff can help consumers when they are in trouble \\
\hline & $\mathrm{C} 7$ & The company is reliable and trustworthy \\
\hline & $\mathrm{C} 8$ & The company can finish the promised service on time \\
\hline & C9 & The order can be recorded correctly in confidential \\
\hline \multirow{3}{*}{ Responsiveness (D3) } & $\mathrm{C} 10$ & The company has a precise time span about the service \\
\hline & $\mathrm{C} 11$ & The service providers could offer the required service timely \\
\hline & $\mathrm{C} 12$ & The staff is happy to assist customers \\
\hline \multirow{4}{*}{ Assurance (D4) } & $\mathrm{C} 13$ & The staff is trustworthy with good reputation \\
\hline & $\mathrm{C} 14$ & Customers have a good experience during the transaction \\
\hline & $\mathrm{C} 15$ & The staff is polite and patient \\
\hline & $\mathrm{C} 16$ & The staff can get support from the company, providing better service \\
\hline \multirow{3}{*}{ Empathy (D5) } & $\mathrm{C} 17$ & The company can provide personalized service specifically \\
\hline & $\mathrm{C} 18$ & The staff can give individual care \\
\hline & C19 & The staff can understand the customers' demands, and interests of customers have the highest priority \\
\hline
\end{tabular}


TABLE 3: The 1-7 scoring scale rule.

\begin{tabular}{lccc}
\hline Score & 1 & 3 & 5 \\
\hline Meaning & Unagree & Agree & Absolutely agree \\
\hline
\end{tabular}

Step 2: employ the pairwise comparison matrices for each of two criteria in terms of the QoS evaluation. The Saaty 1-9 scale is adopted for the pairwise comparison, illustrated in Table 4 [58].

Step 3: undertake the consistency test through equation (4).

Step 4: the relative weight calculation of each criterion through each pairwise comparison.

3.3. TOPSIS Ranking Steps. To prioritize the QoS of terminal delivery subjecting to multiple SERVQUAL criteria, the comprehensive evaluation based multicriteria decision-making technique is usually adopted, such as VIKOR and TOPSIS method. In this study, the TOPSIS technique is employed to achieve the QoS evaluation by measuring and integrating the evaluation value of each alternative $x_{i j}$ in terms of the specific criteria. The TOPSIS steps are similar to previous applications as follows [59].

Step 1: determination matrix establishment: the decision information of each alternative subject to established criteria is denoted as $x_{i j}$, and the matrix is found in the following equation:

$$
p=\left(x_{i j}\right)_{m \times n}=\left\{\begin{array}{cccc}
x_{11} & x_{12} & \cdots & x_{1 n} \\
x_{21} & x_{22} & \cdots & x_{2 n} \\
\vdots & \vdots & \vdots & \vdots \\
x_{m 1} & x_{m 2} & \cdots & x_{m n}
\end{array}\right\} \text {. }
$$

Step 2: normalize the decision matrix by the standardization operation. There are two operations in this step, including homogeneity and normalization in (5) and (6), respectively, the first of which makes all criteria homogeneous; that means the larger the better or the less the better, and the second of which aims at the similar measurement scale.

$$
\begin{aligned}
& x_{i j}^{\prime}=\left\{\begin{array}{l}
x_{i j}, \text { the more thebetter criterion, } \\
\frac{1}{x_{i j}}, \text { the less the better criterion, }
\end{array}\right. \\
& r_{i j}=\frac{x_{i j}^{\prime}}{\sqrt{\sum_{i=1}^{m} x_{i j}^{2}}}
\end{aligned}
$$

where the transformed criteria $x_{i j}$ will become the homogeneous type; namely, the more the better one. The normalized matrix integrating the weighting vector will become

$$
V=\mathbf{R} * \mathbf{W}=\left\{\begin{array}{cccc}
w_{1} r_{11} & w_{2} r_{12} & \cdots & w_{n} r_{1 n} \\
w_{1} r_{21} & w_{2} r_{22} & \cdots & w_{n} r_{2 n} \\
\vdots & \vdots & \vdots & \vdots \\
w_{1} r_{m 1} & w_{2} r_{m 2} & \cdots & w_{n} r_{m n}
\end{array}\right\}
$$

Step 3: determine the positive and negative ideal solution subject to each criterion from all alternatives. The calculation formula is found in equations (8) and (9) in terms of different types, respectively.

$$
\begin{aligned}
A^{+} & =v_{1}^{+}, v_{2}^{+}, \ldots, v_{n}^{+}, \\
& =\left(\max v_{i j} \mid j \in J_{1}\right),\left(\min v_{i j} \mid j \in J_{2}\right)(i=1,2, \ldots, m), \\
A^{-} & =v_{1}^{-}, v_{2}^{-}, \ldots, v_{n}^{-}, \\
& =\left(\max v_{i j} \mid j \in J_{1}\right),\left(\min v_{i j} \mid j \in J_{2}\right)(i=1,2, \ldots, m),
\end{aligned}
$$

where $J_{1}$ is the beneficial criteria (the more the better) and $J_{2}$ is the cost attributes (the less the better).

Step 4: the distance of alternatives from the positive and negative one is calculated by equations (10) and (11).

$$
\begin{aligned}
& D^{+}=\sqrt{\sum_{j=1}^{n}\left(v_{i j}-A^{+}\right)^{2}}, \\
& D^{-}=\sqrt{\sum_{j=1}^{n}\left(v_{i j}-A^{-}\right)^{2} .}
\end{aligned}
$$

Step 5: the relative closeness $R C_{i}$ is derived based on the distance formula, illustrated in the following equation:

$$
R C_{i}=\frac{D_{i}^{M}}{D_{i}^{+}+D_{i}^{-}}, 0 \leq R C_{i} \leq 1
$$

According to the relative closeness value of each alternative, we can prioritize the QoS of express alternative and evaluate terminal delivery. In particular, when $R C_{i}=1$, the alternative will be regarded as the best one. The closeness with best solution reflects the performance of the QoS of the alternatives.

\section{Case Study}

The campus express industry has become the important part in Chinese university daily life. The campus express is a representative application on city express with a vast 
TABLE 4: 1-9 scales for pairwise comparison.

\begin{tabular}{lcc}
\hline Assigned value & Meaning & Detailed explanation \\
\hline 1 & Equally important & The two criteria have the equal importance to the QoS \\
3 & Moderately important & The criterion is moderately important over another \\
5 & Strongly important & The criterion is strongly important over another \\
7 & Very strongly important & The criterion is very strongly important over another \\
9 & Extremely important & The criterion is extremely important over another \\
$2,4,6,8$ & Intermediate value & Used to represent compromise within listed scale above \\
\hline
\end{tabular}

majority of online shopping consumers. In this section, a practical case of terminal delivery in science campus of Zhengzhou University of Light Industry (ZZULI) is conducted to verify the QoS evaluation model.

4.1. Background and Data Collection. The university campus is a typical community with a vast majority of online shopping business for gathered faculties and students. The campus has various express terminals with many kinds of self-service cabinets and delivery outlets, including Shunfeng, Jingdong, Rookie Station, and FengNest which serves different express logistics brands (Shunfeng, Jingdong, Yuantong, and Yunda, etc.). In this section, three typical express alternatives are selected as the evaluation objectives, namely, Shunfeng (A1), Jingdong (A2), and Rookie Station (A3). The developed evaluation framework is employed to evaluate the quality of service of terminal delivery for logistics sector. The data is collected from the student consumers in the campus by the designed questionnaire from the viewpoint of SERVQUAL-based dimensions.

A pilot survey was performed before the main survey, and about 20 consumers in campus were investigated to test the survey approach and ensure the word clarity of the questionnaire. The main survey was conducted from September 2020 to February 2021. The total 597 responses were collected by mail, and the overall response rate was about $59.7 \%$. There are two parts in the questionnaire survey: (1) the demographic information of e-commerce logistics service users in the campus and (2) satisfaction with the terminal delivery. The satisfaction level for each specific criterion was recorded by the Likert five-point scale scoring system $[31,54]$, where the higher scores represent a higher satisfaction. The decision-making information was then generated by collecting the investigation data collected from respondents, illustrated in Table 5.

4.2. Results and Comparison Analysis. Based on the AHPweighting steps, the comprehensive weight of influenced criteria is calculated with $W=(0.0405,0.0193, \ldots, 0.0618$, 0.0753). According to the detail steps of the integrated decision-making framework, the service quality of terminal distribution for objective alternatives is evaluated and calculated in Table 5. In addition, to verify the effectiveness of the proposed integrated decision-making framework, the comparison experiment is performed by exploring VIKOR steps, and the comparison results are found in Table 6 as well. The VIKOR-based method is based on the formula of $L_{p}$-metric subjecting multiple criteria in the following:

$$
L_{p, i}=\left\{\sum_{j=1}^{n}\left[\frac{w_{j}\left(f_{j}^{*}-f_{i j}\right)}{f_{j}^{*}-f_{j}^{-}}\right]^{p}\right\}^{1 / p}, \quad 1 \leq p \leq+\infty, i=1,2, \ldots, m,
$$

where $S_{1}$ is the max group utility value, $R_{i}$ is the minimum individual regret value, and $Q_{i}$ is the comprehensive utility value. The ranking rules of objective alternatives are similar to previous VIKOR applications and publications $[58,60,61]$.

The alternative with higher RC to the ideal solution is regarded as with better quality service; however, candidates with minimum $Q$ value are treated as the best one in VIKOR-based approach. According to the calculated closeness value $(R C)$ of different alternatives, the QoS quality ranking list of terminal distribution is $\mathrm{A} 1>\mathrm{A} 2 \succ \mathrm{A} 3$. From Table 5, the QoS level gets the same ranking result compared with the VIKOR steps. Results show that A1 provides better terminal delivery service compared to other two logistics organizations, and then follows the $\mathrm{A} 2$ brand. In addition, the $\mathrm{C} 8, \mathrm{C} 9, \mathrm{C} 11, \mathrm{C} 14$, and $\mathrm{C} 17$ index have higher criteria weight $(0.097,0.077,0.081,0.085,0.093)$, and A1 has a good performance on these sectors. That is why A1 outperforms the other two brands and gets the first ranking regarding terminal delivery link. It is noteworthy that consumers in ZZULI campus tend to focus on the on-time and personalized service, and the good experience is also significant in terms of terminal delivery link. To improve the terminal delivery service, it is vital to conduct some countermeasures to make sure the punctuality of terminal delivery. Also, the flexibility of terminal delivery can be improved; for instance, the delivery time can be adjusted based on the school time. Logistics company should also pay much more attention to the professionalism cultivation for terminal delivery staffs, and improve consumers' loyalty by providing better delivery service and hospitality experience.

4.3. Theoretical Implications and Managerial Insights. This research serves both scientific and practical contributions to domestic logistics industry by providing some theoretical contributions and practical implications regarding terminal delivery.

In this part, we address the theoretical implications to QoS evaluation of terminal delivery and provide practical insights for logistics sector. The theoretical contributions to existing research are twofold. Firstly, the comprehensive index system is constructed based on SERVQUAL dimensions, and specific 19 criteria are addressed to understand 
TABLE 5: Decision-making information of investigated three alternative brands.

\begin{tabular}{|c|c|c|c|c|c|c|c|c|c|c|}
\hline & $\mathrm{C} 1$ & $\mathrm{C} 2$ & $\mathrm{C} 3$ & $\mathrm{C} 4$ & $\mathrm{C} 5$ & C6 & C7 & $\ldots$ & C18 & C19 \\
\hline $\mathrm{A} 1$ & 0.714 & 0.857 & 0.857 & 0.857 & 0.714 & 0.714 & 0.857 & $\ldots$ & 0.429 & 0.857 \\
\hline A2 & 0.714 & 0.857 & 0.714 & 0.714 & 0.857 & 0.286 & 0.857 & $\ldots$ & 0.429 & 0.857 \\
\hline A3 & 0.429 & 0.571 & 0.429 & 0.429 & 0.429 & 0.429 & 0.571 & $\ldots$ & 0.714 & 0.429 \\
\hline
\end{tabular}

TABLE 6: Results of objective alternatives.

\begin{tabular}{|c|c|c|c|c|c|c|c|c|}
\hline & \multicolumn{4}{|c|}{ The proposed TOPSIS steps } & \multicolumn{4}{|c|}{ The VIKOR-based approach } \\
\hline & $D^{+}$ & $D^{-}$ & $\begin{array}{c}R C \\
\text { value }\end{array}$ & $\operatorname{gg}$ & $S_{i}$ & $R_{i}$ & $Q_{i}$ & ng \\
\hline 41 & 0.06 & & 0.579 & 1 & 58 & 0.0 & 0 & 1 \\
\hline 42 & 0.080 & 0 . & 0.503 & 2 & 0.834 & 0.093 & 0.4 & \\
\hline 43 & 0.087 & 0.068 & 0.439 & 3 & 0.502 & 0.097 & 0.503 & 3 \\
\hline
\end{tabular}

the QoS of terminal delivery regarding the logistics industry. Secondly, an integrated multicriteria decision-making framework is formulated to evaluate the quality of service of terminal delivery business.

From a managerial point of view, the proposed integrated SERVQUAL-AHP-TOPSIS decision-making framework enables logistics managers to better understand the existing quality service level of terminal delivery. Besides, the questionnaire investigation results also assist industrial managers to identify the advantages or disadvantages during the terminal delivery activity. Meanwhile, the unwelcome items obtained from the industrial case can also provide warning on accurate improvement for better service. It is very important for industrial managers to discover the service gap compared to benchmarking brand. This will help logistics organizations to take effective countermeasures to improve their service level.

Regarding as a significant component of online shopping experience, quality service of terminal delivery has obviously affected the consumers' loyalty and willingness to continuously choosing the same brand. From the viewpoint of logistics consumers, this study provides a decision-making framework to choose a most suitable logistics service provider. The quality service evaluation model also provides a general measurement model for logistics sector regarding terminal delivery business.

\section{Conclusions}

The rapid development of online shopping and e-commerce motivates the innovation of modern logistics, including concepts, distribution mode, and optimization models. These industrial applications mainly focus on transportation, distribution, inventory, and network activities, while ignoring the theoretical practices in terms of terminal delivery. As the terminal activity of modern logistics, the quality of service in this link is significant to improve organizational reputation since it provides a face-to-face opportunity to logistics consumers. To discover the QoS of terminal delivery, this study provides an integrated SERUQAL-AHP-TOPSIS framework to evaluate the quality of service. Firstly, the evaluation index system including 19 criteria is established from the viewpoint of SERUQAL dimensions. Secondly, the AHP technique is explored to determine the criteria weight of each indicator. Then, the TOPSIS steps are used to prioritize the QoS level of alternative brands. In addition, the formulated integrated decision-making framework is verified by a practical case in the campus.

Even though the integrated approach provides an effective way to evaluate QoS of terminal delivery activity, there are still some limitations left for future research. Firstly, the influential criteria are constructed based on the basic SERUQAL dimensions, and special index can also be proposed and taken into account based on the regional and cultural discrepancy for different nations. Secondly, the criteria weighting technique is expert-oriented, and the objective-based weighting methods also can be developed by embedding with machine learning techniques. In other words, how to reduce the subjectivity of decision-making by more powerful tools needs to be discussed in the future study. Finally, other MCDM techniques can also be integrated to resolve the QoS evaluation, and the computerbased intelligent technology is also welcome to be embedded with such traditional methods, facilitating the intelligent evaluation.

\section{Data Availability}

The data used to support the findings of this study are available from the corresponding author upon request.

\section{Conflicts of Interest}

The authors declare that they have no conflicts of interest.

\section{Acknowledgments}

This study was financially supported by the Henan Province Philosophy and Social Science Planning Project (2020CZH012). Besides, the authors appreciate Dr. Leiru Wei for her constructive suggestion on their research work.

\section{References}

[1] X. Qin, Z. Liu, and L. Tian, "The strategic analysis of logistics service sharing in an e-commerce platform," Omega-International Journal of Management Science, vol. 92, 2020.

[2] A. Rai, P. A. Pavlou, G. Im, and S. Du, "Interfirm IT capability profiles and communications for cocreating relational value: evidence from the logistics industry," MIS Quarterly, vol. 36, no. 1, pp. 233-262, 2012.

[3] Y. He, F. Zhou, M. Qi, and X. Wang, "Joint distribution: service paradigm, key technologies and its application in the context of Chinese express industry," International Journal of Logistics Research and Applications, vol. 54, pp. 1-17, 2019. 
[4] F. A. Tillman, "The multiple terminal delivery problem with probabilistic demands," Transportation Science, vol. 3, no. 3, pp. 192-204, 1969.

[5] Y. He, M. Qi, F. Zhou, and J. Su, "An effective metaheuristic for the last mile delivery with roaming delivery locations and stochastic travel times," Computers and Industrial Engineering, vol. 145, 2020.

[6] L. Li, X. Wang, Y. Lin, F. Zhou, and S. Chen, "Cooperative game-based profit allocation for joint distribution alliance under online shopping environment," Asia Pacific Journal of Marketing and Logistics, vol. 31, no. 2, pp. 302-326, 2019.

[7] Y. He, X. Wang, F. Zhou, and Y. Lin, "Dynamic vehicle routing problem considering simultaneous dual services in the last mile delivery," Kybernetes, vol. 10, p. 19, 2019.

[8] F. Zhou, Y. He, and L. Zhou, "Last mile delivery with stochastic travel times considering dual services," IEEE Access, vol. 7, pp. 159013-159021, 2019.

[9] L. Zhou, Y. Lin, X. Wang, and F. Zhou, "Model and algorithm for bilevel multisized terminal location-routing problem for the last mile delivery," International Transactions in Operational Research, vol. 26, no. 1, pp. 131-156, 2019.

[10] Y. Li, H. Soleimani, and M. Zohal, "An improved ant colony optimization algorithm for the multi-depot green vehicle routing problem with multiple objectives," Journal of Cleaner Production, vol. 227, pp. 1161-1172, 2019.

[11] F. Zhou and Y. He, "Research on pallet scheduling model with time windows and uncertain transportation time," Engineering Letters, vol. 28, no. 2, pp. 504-509, 2020.

[12] F. Zhou, Y. He, P. Ma, M. K. Lim, and S. Pratap, "Capacitated disassembly scheduling with random demand and operation time," Journal of the Operational Research Society, vol. 23, pp. 1-17, 2021.

[13] L. Calvet, D. Wang, A. Juan, and L. Bové, "Solving the multidepot vehicle routing problem with limited depot capacity and stochastic demands," International Transactions in Operational Research, vol. 26, no. 2, pp. 458-484, 2019.

[14] A. Almouhanna, C. L. Quintero-Araujo, J. Panadero, A. A. Juan, B. Khosravi, and D. Ouelhadj, "The location routing problem using electric vehicles with constrained distance," Computers \& Operations Research, vol. 62, Article ID 104864, 2019.

[15] F. L. Zhou, X. Wang, Y. D. He, and M. Goh, "Production lot-sizing decision making considering bottle-neck drift in multi-stage manufacturing system," Advances in Production Engineering \& Management, vol. 12, no. 3, pp. 213-220, 2017.

[16] F. Zhou, Y. He, L. Deng, and M. Wang, "A novel Bi-level programming model for cloud logistics resources allocation," Journal of Computers (Taiwan), vol. 30, no. 6, pp. 16-30, 2019.

[17] J.-J. Wu, J.-N. Hwang, O. Sharkhuu, and B. Tsogt-Ochir, "Shopping online and off-line? complementary service quality and image congruence," Asia Pacific Management Review, vol. 23, no. 1, pp. 30-36, 2018.

[18] J. W. J. Weltevreden, "B2C e-commerce logistics: the rise of collection-and-delivery points in The Netherlands," International Journal of Retail \& Distribution Management, vol. 36, no. 8-9, pp. 638-660, 2008.

[19] Y.-H. Hsu, "An effective pricing model for the congestion alleviation of e-commerce logistics," Computers \& Industrial Engineering, vol. 129, pp. 368-376, 2019.

[20] D. A. Guerra-Zubiaga, "Intelligent E-commerce logistics platform using hybrid agent based approach," Transportation Research, vol. 126, pp. 15-31, 2019.

[21] D. V. W. X. Zhou Lin and R. Baldacci, "A multi-depot twoechelon vehicle routing problem with delivery options arising in the last mile distribution," European Journal of Operational Research, vol. 265, no. 2, pp. 765-778, 2017.

[22] Y. He, X. Wang, Y. Lin, and F. Zhou, "Optimal partner combination for joint distribution alliance using integrated fuzzy EW-AHP and TOPSIS for online shopping," Sustainability, vol. 8, no. 4, pp. 341-356, 2016.

[23] D. Pandit, "Determination of appropriate service delivery level for quantitative attributes of household toilets in rural settlements of India from users' perspective," Environmental Management, vol. 61, no. 4, pp. 637-649, 2018.

[24] F. T. S. Chan, H. K. Chan, H. C. W. Lau, and R. W. L. Ip, “An AHP approach in benchmarking logistics performance of the postal industry," Benchmarking: An International Journal, vol. 13, no. 6, pp. 636-661, 2006.

[25] F. Lei, G. Wei, H. Gao, J. Wu, and C. Wei, "TOPSIS method for developing supplier selection with probabilistic linguistic information," International Journal of Fuzzy Systems, vol. 22, no. 3, pp. 749-759, 2020.

[26] M. K. Anser, M. Mohsin, Q. Abbas, and I. S. Chaudhry, "Assessing the integration of solar power projects: SWOTbased AHP-F-TOPSIS case study of Turkey," Environmental Science and Pollution Research, vol. 27, no. 25, pp. 3173731749, 2020.

[27] D. Xu, J. Ren, L. Dong, and Y. Yang, "Portfolio selection of renewable energy-powered desalination systems with sustainability perspective: a novel MADM-based framework under data uncertainties," Journal of Cleaner Production, vol. 275, 2020.

[28] S. Roy and S. Bhatia, "Service quality versus service experience: an empirical examination of the consequential effects in B2B services," Industrial Marketing Management, vol. 43, 2019.

[29] F. Zhou, M. K. Lim, Y. He, and S. Pratap, "What attracts vehicle consumers' buying: a Staay scale-based VIKOR (SSCVIKOR) approach from after-sales textual perspective?," Industrial Management \& Data Systems, vol. 120, no. 1, pp. 57-78, 2020.

[30] F. O. Sari, C. Bulut, and I. Pirnar, "Adaptation of hospitality service quality scales for marina services," International Journal of Hospitality Management, vol. 54, pp. 95-103, 2016.

[31] R. C. P. Wong and W. Y. Szeto, "An alternative methodology for evaluating the service quality of urban taxis," Transport Policy, vol. 69, pp. 132-140, 2018.

[32] G. Tuzkaya, B. Sennaroglu, Z. T. Kalender, and M. Mutlu, "Hospital service quality evaluation with IVIF-PROMETHEE and a case study," Socio-Economic Planning Sciences, vol. 44, 2019.

[33] S.-W. Hsu, F. Qing, C.-C. Wang, and H.-L. Hsieh, "Evaluation of service quality in facebook-based group-buying," Electronic Commerce Research and Applications, vol. 28, pp. 30-36, 2018.

[34] J. Sayareh, S. Iranshahi, and N. Golfakhrabadi, "Service quality evaluation and ranking of container terminal operators," The Asian Journal of Shipping and Logistics, vol. 32, no. 4, pp. 203-212, 2016.

[35] J. Kim, J.-D. Schmöcker, J. W. Yu, and J. Y. Choi, "Service quality evaluation for urban rail transfer facilities with Rasch analysis," Travel Behaviour and Society, vol. 13, pp. 26-35, 2018.

[36] S. Scheidt and Q. B. Chung, "Making a case for speech analytics to improve customer service quality: vision, implementation, and evaluation," International Journal of Information Management, vol. 45, pp. 223-232, 2019.

[37] L. Martin-Domingo, J. C. Martín, and G. Mandsberg, "Social media as a resource for sentiment analysis of Airport Service 
Quality (ASQ)," Journal of Air Transport Management, vol. 78, pp. 106-115, 2019.

[38] K. Lee and C. Yu, "Assessment of airport service quality: a complementary approach to measure perceived service quality based on Google reviews," Journal of Air Transport Management, vol. 71, pp. 28-44, 2018.

[39] Y. Su and W. Teng, "Contemplating museums' service failure: extracting the service quality dimensions of museums from negative on-line reviews," Tourism Management, vol. 69, pp. 214-222, 2018.

[40] F. Zhou, X. Wang, and A. Samvedi, "Quality improvement pilot program selection based on dynamic hybrid MCDM approach," Industrial Management \& Data Systems, vol. 118, no. 1, pp. 144-163, 2018.

[41] F. Zhou, X. Wang, Y. Lin, Y. He, and L. Zhou, "Strategic part prioritization for quality improvement practice using a hybrid MCDM framework: a case application in an auto factory," Sustainability, vol. 8, no. 6, 2016.

[42] A. F. Duarte, V. R. Moreira, A. A. Ferraresi, and A. Gerhard, "Evaluating credit union members" perception of service quality through service innovation," RAI Revista de Administração e Inovação, vol. 13, no. 4, pp. 242-250, 2016.

[43] Y. Ju, K.-J. Back, Y. Choi, and J.-S. Lee, "Exploring airbnb service quality attributes and their asymmetric effects on customer satisfaction," International Journal of Hospitality Management, vol. 77, pp. 342-352, 2019.

[44] H. Gupta, "Evaluating service quality of airline industry using hybrid best worst method and VIKOR," Journal of Air Transport Management, vol. 68, pp. 35-47, 2018.

[45] C. Prentice and M. Kadan, "The role of airport service quality in airport and destination choice," Journal of Retailing and Consumer Services, vol. 47, pp. 40-48, 2019.

[46] C.-H. Lee, X. Zhao, and Y.-C. Lee, "Service quality driven approach for innovative retail service system design and evaluation: a case study," Computers \& Industrial Engineering, vol. 135, pp. 275-285, 2019.

[47] K. D. Atalay, B. Atalay, and F. B. Isin, "FIPIA with information entropy: a new hybrid method to assess airline service quality," Journal of Air Transport Management, vol. 76, pp. 67-77, 2019.

[48] A. Meesala and J. Paul, "Service quality, consumer satisfaction and loyalty in hospitals: thinking for the future," Journal of Retailing and Consumer Services, vol. 40, pp. 261-269, 2018.

[49] B. Alonso, R. Barreda, L. Dell'Olio, and A. Ibeas, "Modelling user perception of taxi service quality," Transport Policy, vol. 63, pp. 157-164, 2018.

[50] F. Marimon, J. Llach, M. Alonso-Almeida, and M. MasMachuca, "CC-Qual: a holistic scale to assess customer perceptions of service quality of collaborative consumption services," International Journal of Information Management, vol. 49, pp. 130-141, 2019.

[51] B. Grew, C. R. Schneider, A. Mirzaei, and S. R. Carter, "Validation of a questionnaire for consumers' perception of service quality in community pharmacy," Research in Social and Administrative Pharmacy, vol. 15, no. 6, pp. 673-681, 2019.

[52] L. Eboli, C. Forciniti, and G. Mazzulla, "Spatial variation of the perceived transit service quality at rail stations," Transportation Research Part A: Policy and Practice, vol. 114, pp. 67-83, 2018.

[53] Y. Yang and C. Huang, "DC fault location in multi-terminal DC distribution network based on voltage similar triangle principle," Electric Power Systems Research, vol. 184, Article ID 106306, 2020.
[54] F.-L. Zhou, X. Wang, Y. Lin, Y.-D. He, and N. Wu, "Influence research of multi-dimensional tech-innovation behavior on tech-innovation performance," International Journal of Innovation Science, vol. 8, no. 2, pp. 148-160, 2016.

[55] G. Büyüközkan and G. Çifçi, "A novel hybrid MCDM approach based on fuzzy DEMATEL, fuzzy ANP and fuzzy TOPSIS to evaluate green suppliers," Expert Systems with Applications, vol. 39, no. 3, pp. 3000-3011, 2012.

[56] S. K. Mangla, P. Kumar, and M. K. Barua, "Risk analysis in green supply chain using fuzzy AHP approach: a case study," Resources, Conservation and Recycling, vol. 104, pp. 375-390, 2015.

[57] F. Zhou, Y. Lin, X. Wang, L. Zhou, and Y. He, "ELV recycling service provider selection using the hybrid MCDM method: a case application in China," Sustainability, vol. 8, no. 5, 2016.

[58] D. Prajapati, F. Zhou, M. Zhang, H. Chelladurai, and S. Pratap, "Sustainable logistics network design for multiproducts delivery operations in B2B e-commerce platform," Sādhanā, vol. 46, no. 2, pp. 1-13, 2021.

[59] Y. He, X. Wang, Y. Lin, F. Zhou, and L. Zhou, "Sustainable decision making for joint distribution center location choice," Transportation Research Part D: Transport and Environment, vol. 55, pp. 202-216, 2017.

[60] S. Opricovic and G.-H. Tzeng, "Compromise solution by MCDM methods: a comparative analysis of VIKOR and TOPSIS," European Journal of Operational Research, vol. 156, no. 2, pp. 445-455, 2004.

[61] F. Zhou, X. Wang, M. K. Lim, Y. He, and L. Li, "Sustainable recycling partner selection using fuzzy DEMATEL-AEWFVIKOR: a case study in small-and-medium enterprises (SMEs)," Journal of Cleaner Production, vol. 196, pp. 489-504, 2018. 